\title{
High Power MPD Thruster Development at the NASA Glenn Research Center
}

Michael R. LaPointe and Pavlos G. Mikellides

Ohio Aerospace Institute, Brook Park, Ohio

Prepared for the

37th Joint Propulsion Conference and Exhibit cosponsored by the AIAA, ASME, SAE, and ASEE

Salt Lake City, Utah, July 8-11, 2001

Prepared under Cooperative Agreement NCC3-860

National Aeronautics and

Space Administration

Glenn Research Center 


\section{Acknowledgments}

This research is supported through the Ohio Aerospace Institute under NASA Cooperative Agreement NCC3-860.

The authors express their gratitude to Gene Strzempkowski, Joseph Dick, and George Rodriguez for the design

and construction of the MW-class capacitor bank, pulse-forming network, and related control systems; to

Jim Coy for the modified design and construction of the pulsed propellant feed system; to Stan Grisnik and Robert Roman for refurbishing the VF-1 pumping and control systems, and to Nicholas Iosue,

Derrick Patterson, Douglas Warren, Roberto DuBreuil, and their Akima Corporation colleagues

for the construction of the thrust stand and related test hardware. The successful construction and operation of the high power MPD thruster test facility is a reflection of

their skill and dedication.

This report is a formal draft or working paper, intended to solicit comments and ideas from a technical peer group.

This report contains preliminary

findings, subject to revision as analysis proceeds.

Available from

NASA Center for Aerospace Information

7121 Standard Drive

National Technical Information Service 5285 Port Royal Road

Hanover, MD 21076

Springfield, VA 22100

Available electronically at http://gltrs.grc.nasa.gov/GLTRS 


\title{
HIGH POWER MPD THRUSTER DEVELOPMENT AT THE NASA GLENN RESEARCH CENTER
}

\author{
Michael R. LaPointe and Pavlos G. Mikellides \\ Ohio Aerospace Institute \\ Brook Park, Ohio 44142
}

\begin{abstract}
Propulsion requirements for large platform orbit raising, cargo and piloted planetary missions, and robotic deep space exploration have rekindled interest in the development and deployment of high power electromagnetic thrusters. Magnetoplasmadynamic (MPD) thrusters can effectively process megawatts of power over a broad range of specific impulse values to meet these diverse in-space propulsion requirements. As NASA's lead center for electric propulsion, the Glenn Research Center has established an MW-class pulsed thruster test facility and is refurbishing a high-power steady-state facility to build and test efficient gas-fed MPD thrusters. A complimentary numerical modeling and thruster design effort based on the robust $\mathrm{MACH} 2$ code provides a well-balanced program of numerical analysis and experimental validation leading to improved high power MPD thruster performance. This paper reviews the current and planned experimental facilities and numerical modeling capabilities at the Glenn Research Center, and outlines program plans for the development of new, efficient high power MPD thrusters.
\end{abstract}

\section{INTRODUCTION}

High power electric propulsion offers significant advantages over chemical systems for platform orbitraising, lunar and planetary cargo missions, and robotic and piloted planetary and deep space exploration missions. . $2.2 .4^{2.4}$ As the lead NASA center for electric propulsion, the Glenn Research Center (GRC) is developing high power electromagnetic thruster technologies to meet these demanding propulsion requirements. This paper presents an overview of the GRC program to design and test new, efficient high power $(0.1-\mathrm{MW}$ to $10-\mathrm{MW})$ magnetoplasmadynamic (MPD) thruster technologies.

In its most basic form, the MPD thruster consists of a central cathode surrounded by a concentric cylindrical anode (Fig.1). A high-current arc is struck between the anode and cathode, which ionizes and accelerates a gas propellant. In self-field thrusters, an azimuthal magnetic field produced by the return current flowing through the cathode interacts with the radial discharge current density flowing through the plasma to produce an axial body force. In applied-field versions of the thruster, a solenoid magnet surrounding the anode is used to provide additional radial and axial magnetic fields that can help stabilize and accelerate the plasma discharge.

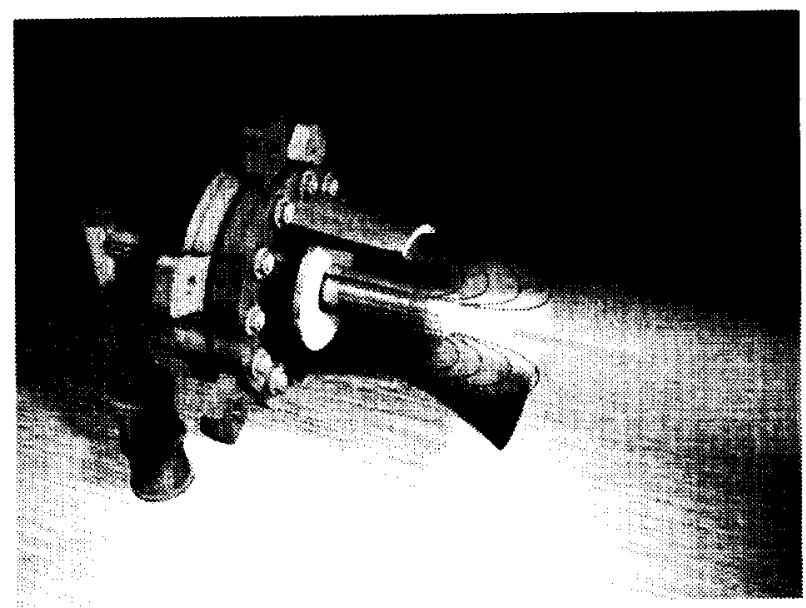

Figure 1. MPD thruster diagram. (Courtesy J. MacNeill)

The MPD thruster has had a long if intermittent history of development, and several review papers have been written over the past several years that chronicle both the progress and challenge of this promising propulsion 
technology. ${ }^{5.67}$ MPD thrusters have been operated with a variety of propellants, with the most efficient thruster performance to date obtained using vaporized lithium. Lithium-fed MPD thrusters developed by the Moscow Aviation Institute in Russia recently demonstrated $45 \%$ efficiency at power levels exceeding $100-\mathrm{kW}^{8}{ }^{8}$ and lithium-fed devices are currently being developed in the United States by the NASA Jet Propulsion Laboratory and Princeton University. ${ }^{9,10}$ A potential issue with lithium is that it is a condensable propellant, and has the potential to coat spacecraft surfaces and instruments. Alternate non-condensable gas propellants have been investigated, but the performance has typically been less efficient than lithium propellant. ${ }^{6.711}$ However, recent theoretical models indicate that significantly improved performance can be obtained with gas-fed MPD thrusters through the use of modified electrode geometries and the proper application of applied magnetic fields. ${ }^{12.13}$ The use of gas propellants mitigates potential handling and spacecraft contamination issues associated with lithium, and provides for thruster operation with various propellants over a wide range of specific impulse values.

The remainder of this paper describes the theoretical and experimental program currently underway at the NASA Glenn Research Center to develop and test gas-fed MPD thrusters. The GRC MW-class pulsed thruster facility is described in the next section, followed by an overview of the planned MW-class steady-state thruster test facility anticipated to be online in FY03. Following the experimental program description is an overview of the MACH2 code numerical modeling effort, and recent insights into MPD thruster operation provided through $\mathrm{MACH} 2$ simulations. The paper concludes with a brief summary of planned Glenn Research Center activities to develop efficient, high power MPD thrusters for near and mid-term mission applications.

\section{EXPERIMENTAL FACILITIES}

Prior MPD thruster experiments at NASA GRC were discontinued in the early 1990s, coinciding with the termination of the Space Exploration Initiative and a dramatic decrease in program funds for high power electric propulsion system development. Power and control systems for a $600-\mathrm{kW}$ steady-state thruster test facility were mothballed and eventually removed and reused in other programs. With the advent of renewed interest in high power thrusters, GRC embarked on the development of a pulsed test facility to evaluate MW-class MPD thruster designs. This facility is now online, and is described in detail in the sections below. Plans to bring the previous steady-state MPD thruster test facility back online, with an increase in power to 1-MW, are also described.

\section{Pulsed Thruster Facility}

Planning for the GRC MW-class pulsed thruster test facility was initiated in FY99, with the facility becoming fully operational in FY01. A high-energy capacitor bank and pulse-forming network were designed and built, the vacuum test facility was refurbished, and an impulse-based thrust stand was fabricated for pulsed MPD thruster operation.

Capacitor Bank. The capacitor bank consists of 46 capacitors and 7 inductors arranged in a 7 -element Guillemin pulse-forming network (PFN; Fig 2). Each capacitor is rated for $10-k V D C$, with an expected shot life

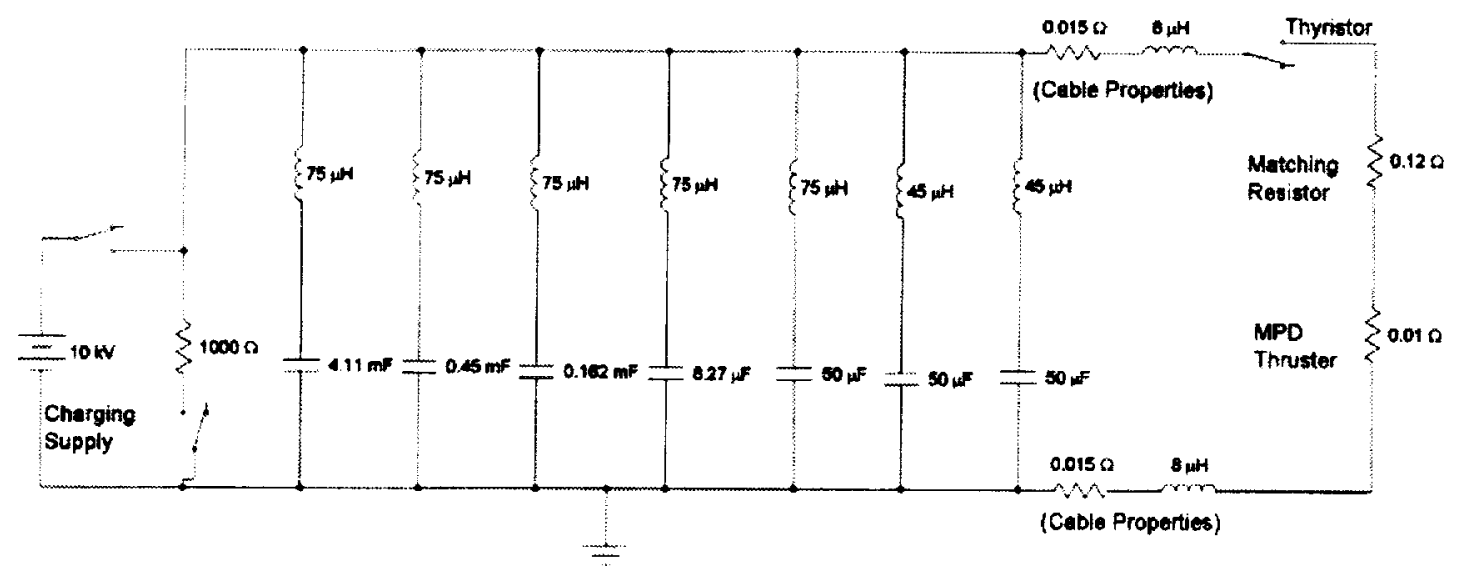

Figure 2. Diagram of capacitor bank and pulse forming network. 
of $10^{4}$ discharges at maximum voltage. The total bank capacitance is $4.88-\mathrm{mF}$, providing a maximum stored energy of $250-\mathrm{kJ}$ at full charge. The discharge period is approximately $2 \times 10^{-3} \mathrm{~s}$, with less than $10 \%$ current ripple over the discharge plateau. Switching is performed by a solid-state thyristor rated for $15-\mathrm{kV}$ and $50-\mathrm{kA}$ peak current, although the bank can also be fired using an available triggered spark-gap switch. The inductors consist of insulated 3/8" copper tubing wound around short sections of $10.75^{\prime \prime}(27.3 \mathrm{~cm})$ OD pvc pipe. A $0.12 \Omega$ matching resistor, rated for $10-\mathrm{kV}$ and $250-\mathrm{kJ}$, is located in series between the switch and load. Representative current and voltage traces obtained with a $0.13-\Omega$ resistive load used to simulate a typical MPD thruster discharge are presented in Figure 3. A 1000- $\Omega$, 250-kJ resistor tied across the bank is used to discharge the

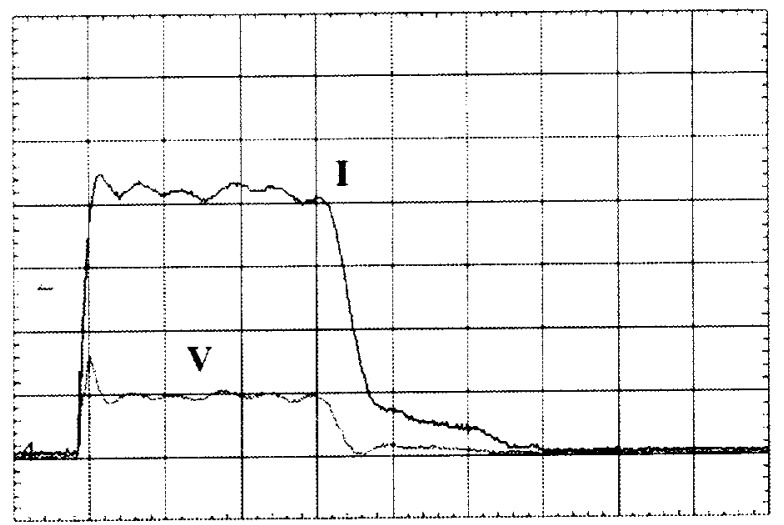

Figure 3. Voltage and current waveforms for $13-\mathrm{m} \Omega$ resistive load. Bank charged to $3-\mathrm{kV}$. Terminal voltage $=54 \mathrm{~V}$, current $=8400 \mathrm{~A} .500 \mu \mathrm{s} /$ division

capacitors in the event of a thruster malfunction or safety interlock violation. The approximate physical dimensions of the capacitor bank are $4.5 \mathrm{~m}(15 \mathrm{ft}$ ) long by $2.1 \mathrm{~m}$ ( $7 \mathrm{ft}$ ) high by $0.9 \mathrm{~m} \mathrm{(} 3 \mathrm{ft}$ ) wide. A portion of the capacitor bank and PFN are shown in Figure 4.

Vacuum Chamber. Pulsed MPD thruster testing is conducted in GRC Vacuum Facility 1 (VF1). The vacuum chamber, shown in Figure 5 , is $1.5-\mathrm{m}(5 \mathrm{ft})$ in diameter by $4.5-\mathrm{m}$ ( $15 \mathrm{ft}$ ) long. Access to the chamber interior is provided through a flat endcap mounted on a balanced swing-arm. The tank is pumped by two $0.8-\mathrm{m}$ (32") oil diffusion pumps backed by a mechanical blower, and is capable of reaching an unloaded base pressure of $10^{-6}$ torr $\left(8 \times 10^{-9} \mathrm{~Pa}\right)$. The vacuum tank is located on the floor immediately above the capacitor bank, and power is cabled to the tank through high voltage feedthroughs located on a $1-\mathrm{m}\left(36^{\prime \prime}\right)$ bottom flange. Instrumentation

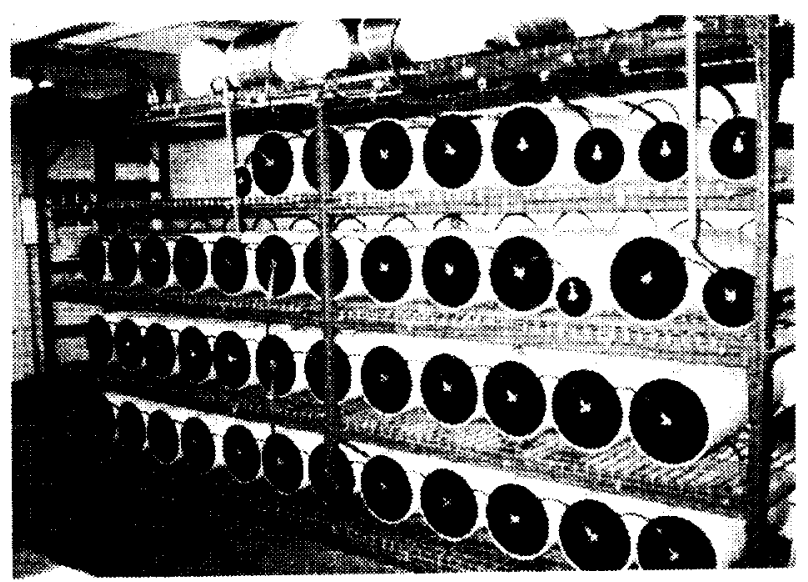

Figure 4. Partial view of capacitor bank. Inductors mounted along top rack. Solid-state switch is not shown.

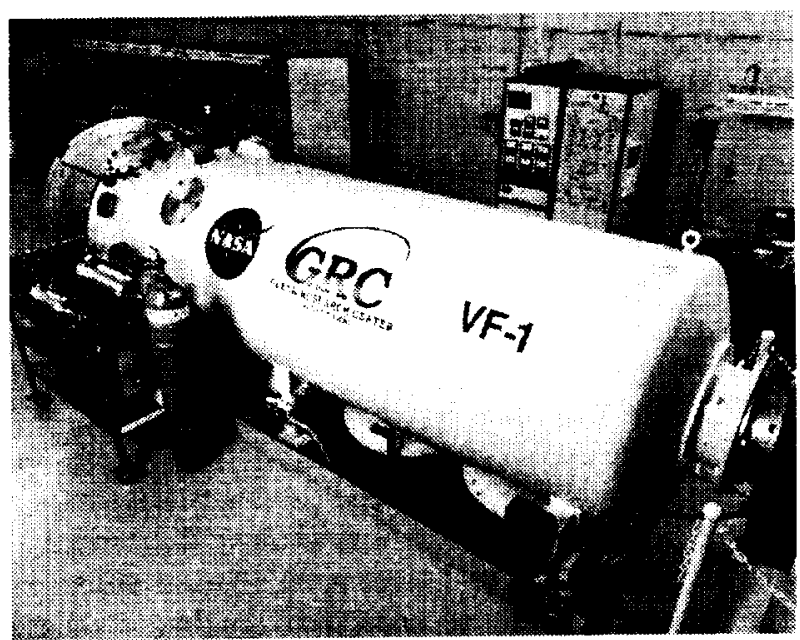

Figure 5. VF-1 vacuum chamber and propellant plenum test cart.

and gas feedthroughs are located on a $0.4-\mathrm{m}$ (16") side port, with additional access available through several $0.1-\mathrm{m}$ (4") ports mounted to the facility endcap. A separate 0.4-m side port provides power cable access for a magnetic field coil, described in a later section of the paper.

Propellant Plenum. The propellant gas plenum is mounted to a test cart located beside VF1 (Fig. 5). The cylindrical plenum chamber is constructed of stainless steel, with an interior volume of $2.5 \times 10^{-2} \mathrm{~m}^{3}\left(1.5 \times 10^{3} \mathrm{in}^{3}\right)$. Stainless steel tubing connects one end of the plenum to a regulated gas bottle, while the other end is connected to a pneumatic actuator powered by a fast acting solenoid valve. Gas flow from the actuator can be directed either through a side flange into the VF- 1 test chamber or to a small calibration chamber located on the test cart. The 
cylindrical calibration chamber, also constructed of stainless steel, has an internal volume of $6.1 \times 10^{-3} \mathrm{~m}^{3}$ $\left(3.7 \times 10^{2} \mathrm{in}^{3}\right)$ and is used to measure the amount of gas discharged during pulsed plenum operation. Both the propellant plenum and the calibration chamber are outfitted with wide-ranging pressure gauges (dual pirani gauge and diaphragm manometer), capable of measuring pressure values from $10^{-3}$ torr to 1500 torr. During calibration, the propellant plenum pressure is set to a given value, and the calibration chamber is evacuated to vacuum. Gas from the propellant plenum is discharged into the calibration plenum, and the resulting pressure rise is recorded. Knowing the pressure change and the chamber volume allows the propellant mass injected into the calibration chamber to be calculated, and dividing this mass by the total response period of the pneumatic actuator provides the propellant flow rate for the pulsed discharge. The response time of the actuator can be set between 60-ms and 180-ms through the use of a variable resistor in the control circuit; the latter value has been used to reduce the effect of uncertainty in the actuator opening and closing response times. The calibrated mass flow rates are estimated to have maximum uncertainties of $\pm 5 \%$.

Applied-Field Magnet. Prior research has shown that it is often advantageous to operate MPD thrusters with applied magnetic fields. ${ }^{6.7 .12 .13}$ To provide this capability, 4-AWG insulated cabling was wound on a 0.2-m (8") OD pvc pipe to form a solenoid test magnet. The magnet consists of 7 layers with 18 turns per layer. The magnet cabling is uncooled, limiting both the maximum current and period of operation. but the simplicity of operation and the attainable field strength over the required thruster pulse period outweigh these disadvantages. Power is supplied by a $50-\mathrm{kW}$ constant-current arc welder, capable of delivering up to 1000 A to the magnet. The axial magnetic field strength at the center of coil as a function of current is approximately $5 \times 10^{-1} \mathrm{~T} / \mathrm{A}$, while at the end of the coil the axial field is along the centerline is approximately $3.3 \times 10^{-4} \mathrm{~T} / \mathrm{A}$.

Control System. The events leading up to a pulsed thruster discharge are controlled by an automated sequencing system mounted in the MPD control rack. If the applied-field magnet is to be used, the arc welder is set to the desired current level. The capacitor bank is then charged to the desired voltage using a $4-\mathrm{kW}, 10-\mathrm{kV}$ power supply located in the control rack. Once the bank is charged to the desired voltage, the charging supply is disengaged and the test sequence is initiated. The magnet power is turned on for a period of $4.5 \mathrm{~s}$, sufficient to establish a constant field distribution within the thruster and allow any residual thrust stand disturbances due to turning on the magnet to damp away. Toward the end of this period, the propellant plenum solenoid is activated to provide a gas pulse to the thruster; as noted, the duration of the gas pulse can be set from $60-\mathrm{ms}$ to $180-\mathrm{ms}$, with the present value set at 180 -ms to reduce uncertainties in the pulsed propellant mass flow rate. The capacitor bank switch is triggered toward the end of the gas flow period, providing a 2-ms, high current discharge to the thruster. Once the bank has fired, the control sequence turns off the gas flow and magnet current, and the logic system is then reset to initiate another test sequence.

Thrust Stand. The impulse thrust stand is based on a simple flexure design (Fig. 6). The thruster is mounted to a stiff plate, which in turn is supported by four thin, contoured aluminum flexures. Current is fed to

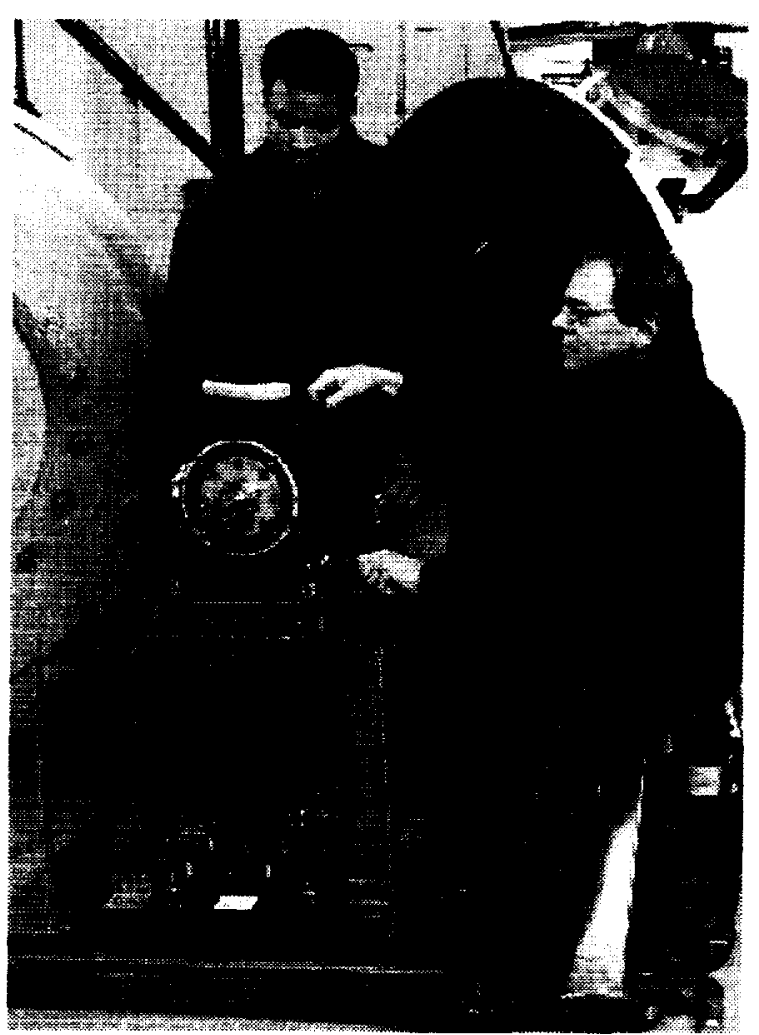

Figure 6. Applied-field quasi-steady MPD thruster mounted to flexure-based thrust stand. 
the thruster through flexible braided copper cables mounted on each side of the stand. Upon discharge, the thrust stand is horizontally displaced by the thruster impulse. An LVDT transducer is used to measure thrust stand displacement for the larger oscillations occurring at high discharge powers, while strain gages mounted to the flexures are used to measure smaller displacements. The thrust stand is calibrated using a fixed-length pendulum that provides non-elastic momentum transfer to the stand. Varying the angle at which the pendulum is released varies the impulse delivered to the stand, allowing displacement to be measured as a function of impulse. The present thrust stand does not allow in-situ calibration under vacuum conditions; however, a solid-state inclinometer mounted beneath the top plate of the thrust stand is used to provide information on the initial and final orientation (tilt) of the stand. No significant differences have been observed between thrust stand orientations at rest in air or under vacuum, providing some assurance that the measured impulse values will closely correspond to the calibrated thrust stand values. Nevertheless, the angular orientation of the stand before and after each shot is recorded to allow refined calculations of the delivered impulse, if required.

Data Collection. The primary diagnostics at this stage of facility development include thruster voltage and current, thrust stand displacement, and magnet coil temperature. Measurements of the thruster voltage and current allow the thruster power to be calculated; combined with thrust measurements supplied by the thrust stand displacement, the efficiency of the thruster can then be determined. These basic measurements serve the main purpose of the pulsed thruster facility: to develop an efficient MPD thruster design prior to undertaking more extensive steady-state development and testing.

Digital oscilloscopes are used to measure and record voltage and current waveforms at the capacitor bank and at the thruster or resistive load. Differential voltages are read across the thruster electrodes and across the solid-state switch. Voltage attenuation (resistor network) circuits are used to scale the voltage channels to prevent waveform clipping by the oscilloscopes. Current monitors (transformers) are used to measure the pulsed current at the output of the capacitor bank and at the input to the thruster, providing independent measurements of the discharge current. The coils are rated for $50-\mathrm{kA}$ peak current, a current-time product of $65 \mathrm{~A}-\mathrm{s}$, and a rise time of $2.5 \times 10^{-7} \mathrm{~s}$. Voltage and current waveforms are transferred from the oscilloscope to a stand-alone desktop computer for later analysis.
As previously noted. the impulsive force delivered to the thrust stand during a thruster discharge is measured by a LVDT transducer at high impulse values and strain-gages mounted to flexure supports at low impulse values. Transducer or strain-gage voltage signals are sent through a 9-pin vacuum feedthrough to a desktop computer data acquisition system, where the data is recorded for later analysis. The thruster temperature is not expected to rise significantly during each discharge, and the period between discharges is sufficiently long that thruster electrode temperature measurements are not required. However, the magnet coil current will resistively heat the applied-field magnet, and thermocouples have been embedded in the coil to monitor the temperature rise and signal when testing should be suspended to cool the magnet. Hall and Langmuir probe plasma diagnostics will be installed in the pulsed thruster facility at the beginning of the next fiscal year.

\section{Steady-State Thruster Facility}

To evaluate steady-state thruster performance, as well as investigate a number of related material and life issues, a MW-class steady-state MPD thruster test facility is currently being refurbished at the NASA Glenn Research Center. Prior steady-state, $100-\mathrm{kW}$ class MPD thruster experiments were performed at the Glenn Research Center during the late $1980^{\circ}$ s through the early 1990's, when MPD research was terminated due to NASA budgetary constraints. Results of that effort have been described elsewhere. and the reader is referred to the original papers and the references therein. ${ }^{7.14 .15 .16 .17 .18}$ Several major pieces of test equipment remain from the earlier program, and the primary power and control systems are currently undergoing repair or replacement to provide up to $1-\mathrm{MW}$ of uninterrupted power to the test facility. The result of this multi-year upgrade will be a world-class test chamber capable of supporting steadystate MW-class MPD thruster experiments. The following sections provide a brief overview of the major components of this facility, which is slated to begin high power MPD thruster operation in 2003.

Vacuum Chamber. The vacuum chamber, designated VF-5, is a $4.6-\mathrm{m}$ ( $15 \mathrm{ft}$ ) diameter by $18.3-\mathrm{m}$ $(60 \mathrm{ft})$ facility pumped by twenty $0.8-\mathrm{m}$ ( $32 \mathrm{in}$ ) diffusion pumps, which in turn are backed by four root blowers and four mechanical pumps. The facility is capable of attaining an unloaded base pressure of $4 \times 10^{-7}$ torr $\left(3 \times 10^{-9}\right.$ Pa), and can pump $2.5 \times 10^{4} \mathrm{l} / \mathrm{s}$ of air while maintaining a chamber pressure of $10^{-5}$ torr. In addition to the diffusion pumps, the facility is outfitted with a $33.5-\mathrm{m}^{2}$ helium 
cryopanel that increases the total pumping capability to $1.5 \times 10^{\circ} \mathrm{l} / \mathrm{s}$ of air at a chamber pressure at $10^{-6}$ torr. The vacuum facility is fully automated, and provides a number of gated test ports and instrumentation feedthroughs to support a wide variety of experimental requirements.

Infrastructure. Although most of the MPD thruster control systems were removed in the early 1990s, some power supplies and water-cooling lines remain intact. Additional power capability will be added to the facility, bringing the total available power to $1-\mathrm{MW}$. Water-cooling pumps will be reinstalled to provide heat rejection for steady state, high power thruster operation. The thruster control system will be replaced, as most of the original components were cannibalized for use in other electric propulsion test programs. An existing thrust stand, based on an inverted pendulum design ${ }^{14}$ and used in the prior MPD thruster test program, will be refurbished and modified for MW-class operation. A calibrated propellant mass flow system will be retrieved from storage and refurbished, along with several equipment racks and control consoles. Instrumentation, such as terminal voltage and current monitors, will need to be replaced, as will more advanced diagnostic systems such as motion-controlled Langmuir and Hall probes. Fortunately the facility and control schematics from the previous MPD thruster test program were well documented, and will allow a fairly smooth transition to higher power operation.

\section{Pulsed vs. Steady State Operation}

The pulsed thruster test facility provides an economical testbed for the evaluation of MW-class MPD thruster designs prior to more extensive testing under steady-state conditions. Novel thruster designs can be quickly constructed and tested to gauge their potential performance during high power operation, with only the most promising thruster concepts promoted for further steady-state development and testing. Although pulsed operation does not capture all of the performance variables encountered in steady-state thruster operation, the pulsed high power tests are sufficient to determine viable designs for efficient $\mathrm{MW}$-class operation. In support of this approach, MPD thruster experiments performed at the University of Stuttgart demonstrated that pulsed thrusters operated at up to several hundred kilowatts provided lower thrust and higher voltage than identical thrusters operated at comparable steady-state power levels, although the discrepancies became less significant as the discharge power was increased. ${ }^{19.20}$ These results indicate that quasi-steady MPD thruster performance will probably be slightly worse than steadystate performance under the same operating conditions. This provides some assurance that an efficient pulsed thruster design may provide better performance under continuous operation, and justifies the use of the pulsed thruster facility as a first step in the development of efficient MW-class thrusters.

\section{MPD THRUSTER MODELING}

Over the last thirty years, development of MPD thrusters has mostly proceeded empirically, thus only pertinent to the specific geometries and operating conditions examined by those experiments. The lack of complete theoretical tools has impeded the general understanding of the interdependent physical processes in self-field thrusters. Several numerical models ${ }^{7}$ have been constructed to study MPD operation. but due to constrained computational resources they have generally approached the problem within over-simplifying assumptions. In the early ' $90 \mathrm{~s}$, a more sophisticated MHD code was employed to study $\mathrm{kW}$-level, applied-field operation with great success. '? The current thruster development program at the Glenn Research Center will once again utilize such a tool along with the insights gained from the previous effort to provide experimental guidance in the design of efficient self-field and appliedfield MPD thrusters operating at MW power levels.

\section{The MACH2 Code}

In the mid-1980s the Mission Research Corporation developed a magnetohydrodynamics (MHD) code under Air Force contract to study collisional plasmas for problems of complex geometries. ${ }^{21}$ Over the years, this Multi-block Arbitrary Coordinate Hydromagnetic (MACH) simulation tool has been utilized to model a diverse range of plasma problems and has been substantially upgraded through contributions from a variety of scientists. It is currently being maintained and upgraded to a three-dimensional solver (MACH3) by The Center for Plasma Theory and Computation at the Air Force Research Laboratory.

$\mathrm{MACH} 2$ is a time-dependent, two-dimensional, axisymmetric, multi-material code that can be applied to problems of complex geometries due to its multi-block structure. ${ }^{22}$ The computational mesh can move in an 
Arbitrary-Lagrangian-Eulerian (ALE) fashion allowing applicability to both diffusive- and dispersive-dominated problems as well as code validation. The mesh can be refined via a variety of adaptive schemes to capture regions of varying characteristic scale. The set of the single-fluid, MHD equations is time-advanced with finite-volume spacial differencing, and the boundary conditions are applied via the ghost-cell technique so that no special conditional statement is necessary at the boundaries.

The mass continuity and momentum equations assume a compressible, viscous fluid with the latter including both real and artificial viscosity effects. The stress-deviator can be chosen to evolve under elastic stress for strength of material calculations ${ }^{23}$ or modeled as a Newtonian fluid to upgrade the code to a Navier-Stokes solver. ${ }^{2+}$ The code includes two ablation models that allow mass addition due to solid evaporation and have been successfully employed to model ablation-fed pulsed plasma thrusters. ${ }^{25}$ The electrons, ions and radiation field are in thermal nonequilibrium, so $\mathrm{MACH} 2$ solves three energy equations. These include thermal conduction with anisotropic transport ${ }^{26}$ and three different models for radiation cooling. ${ }^{21.27}$ Evolution of the magnetic field is prescribed by the induction equation that includes resistive diffusion, the Hall effect and the thermal source for magnetic fields. Various models for the plasma resistivity are available. They comprise classical anisotropic resistivity, ${ }^{26}$ several anomalous resistivity models and contributions from electron-neutral collisions applicable to weakly ionized gases. ${ }^{21}$ In many engineering applications the source of magnetic flux is applied currents produced from externally-applied voltage differentials. For this, the code includes a variety of circuit models such as LRC, PulseForming-Networks, sine-waveforms and several others. Other additional physical models include laser-pulse energy deposition and a detonation package.

The set of the MHD equations is completed by an equation of state that can be either analytic or tabular. The latter is provided by the SESAME library that includes semi-empirical models for the thermodynamic properties, transport coefficients, (including opacities) and average ionization state under local thermodynamic equilibrium. These models have been constructed and are being maintained by the T-1 and T-4 groups at Los Alamos National Laboratory. ${ }^{28}$

NASA/CR-2001-211114
The level of sophistication and capability of the $\mathrm{MACH} 2$ code has been instrumental in providing invaluable insights to a variety of plasma problems. Some of these include plasma opening switches, ${ }^{, 9}$ inertial-confinement fusion and alternative concepts, ${ }^{30}$ compact toroid formation and acceleration schemes, ${ }^{31}$ gas and solid density z-pinch implosion physics, ${ }^{32}$ laser-target interactions, ${ }^{33}$ high-power plasma source design, ${ }^{3+}$ magnetic nozzles ${ }^{35}$ and a variety of plasma thrusters. ${ }^{12.18}$ Its diverse success establishes the code as the primary numerical tool in the development of MW-class MPD thruster designs at NASA GRC.

\section{MW-class Self-field MPD Simulations}

In an effort to provide code validation and useful insights, $\mathrm{MACH} 2$ was employed to model real MW-class thrusters in order to compare to experimental data. The particular thruster selected for the simulations was one of the Japanese $M Y^{36,37}$ family of MPD configurations that was operated with and without external magnetic fields. In this manner, MACH2 could be compared to both selffield and applied-field operation within the power level of interest; $0.5-6 \mathrm{MW}$.

Specifically, the simulated cases addressed the MY-II version of the thruster (Fig. 7) that was operated in the aforementioned power range at a Hydrogen mass flow rate of $1.37 \mathrm{~g} / \mathrm{s}$. The physics included viscosity effects and real equation of state for the propellant gas along with thermal non-equilibrium. Even though available. these simulations did not include non-uniform massinjection schemes as it was shown that such effects were negligible in this regime of operation. The computational

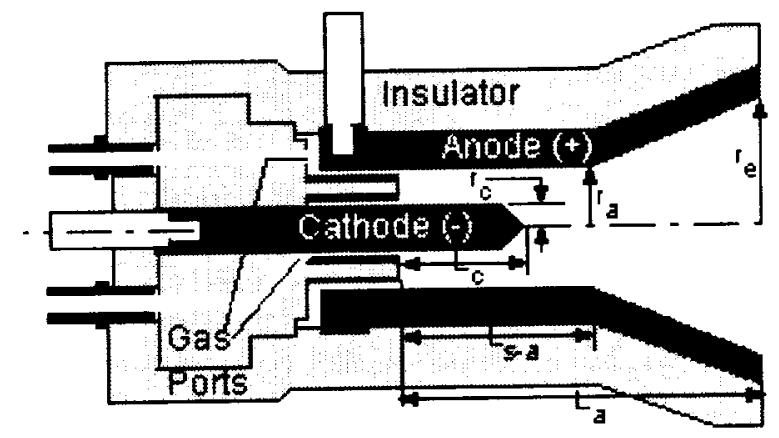

Figure 7. Schematic of the multi-megawatt, MY-II MPD thruster used for the MACH2 simulations. Dimensions in mm: $r_{c}=4.75, r_{a}=25, r_{e}=52, L_{c}=45$, $\mathrm{L}_{\mathrm{s}-\mathrm{a}}=75, \mathrm{~L}_{\mathrm{a}}=104$. 


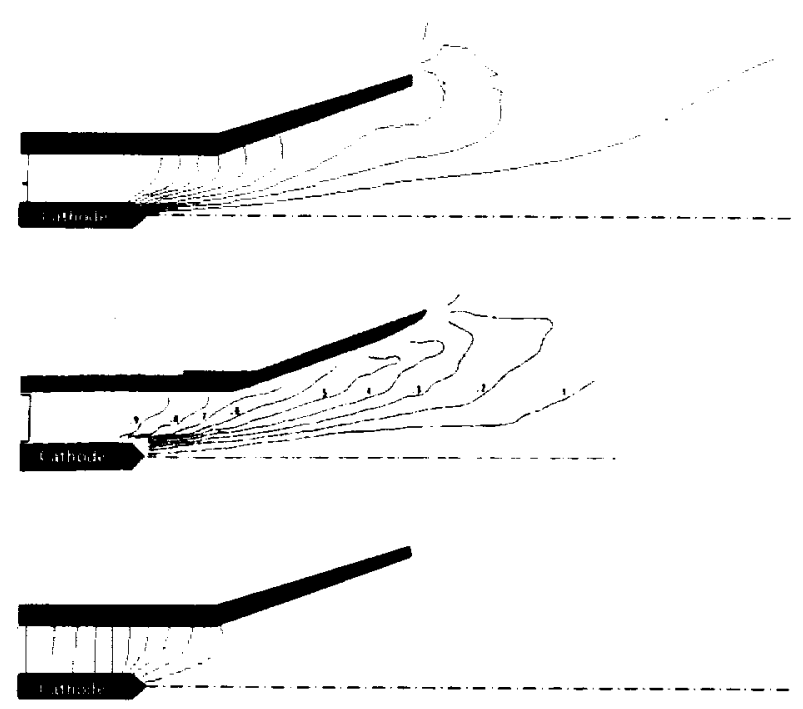

Figure 8. Current Distribution comparisons at 10kA. Top: $\mathrm{MACH} 2$ simulation with electron-neutral collisions included in the resistivity model. Thrust $=36.9 \mathrm{~N}$, Voltage $=183 \mathrm{~V}$.

Middle: Experiment, Thrust $=34 \mathrm{~N}$, Voltage $=200 \mathrm{~V}$, efficiency $=21 \%$.

Bottom: MACH2 simulation with classical resistivity, Thrust $=32.4 \mathrm{~N}$, Voltage $=108 \mathrm{~V}$.

domain extended to $300 \mathrm{~mm}$ in order to capture plume processes such as current distension and thus additional acceleration. For this. calculation of thrust and deposition to various energy modes was performed at the outlet boundaries of the computational region. The solidelectrode boundary conditions were no-slip, electrical conductors with thermal conduction modeled at a constant wall temperature. These temperature values were chosen at $1000 \mathrm{~K}$ for the anode and $2000 \mathrm{~K}$ for the cathode consistent with experimental measurements. ${ }^{36}$

Comparisons of the steady state simulations to the experimental data for a discharge current of $10 \mathrm{kA}$ (Fig. 8) were quite favorable and provided new insights that demanded further interrogation. Principally, they have identified the importance of electron-neutral collisions in this regime of operation, especially with respect to energy deposition. In particular, the plasma electrical diffusivity in $\mathrm{MACH} 2$ can be modeled to include contributions from such collisions as follows (shown in scalar form):

$$
\bar{\eta}=1.0328 \times 10+\frac{\bar{\zeta} \ln \Lambda}{\mu_{0} \mathrm{~T}_{\mathrm{e}}^{3 / 2}}+\frac{\sigma_{\mathrm{e}}}{\mu_{\mathrm{e}} \mathrm{e}} \frac{1-\zeta}{\zeta} \sqrt{\frac{\mathrm{m}_{\mathrm{e}} \mathrm{T}_{\mathrm{e}}}{\mathrm{e}}} \mathrm{m}^{2} / \mathrm{s}(1)
$$

where $T_{e}$ is the electron temperature in $\mathrm{eV}, \mathrm{e}$ is the elementary charge, $m_{e}$ is the electron mass, $\zeta$ is the mean ionization $(\zeta>1), \mu_{0}$ is the permeability of free space, $\ln \Lambda$ is the Coulomb logarithm and $\sigma_{e}$ is an appropriate collision cross-section. For Hydrogen this electronneutral collision cross section was taken at $5 \times 10^{-19} \mathrm{~m}^{2}$ as a reasonable average over a range of electron energies. ${ }^{38}$ The first term represents the classical Spitzer-Härm formulation while the second is additive and accounts for electron-atom collisions.

Exclusion of such a contribution implied that the major energy losses are due to fall voltages and other external circuit losses as it dramatically underestimated the total experimental voltage (Fig. 8). Specifically, the difference of $92 \mathrm{~V}$ between the calculated plasma voltage and the experimental total voltage suggests that such losses are of the order of $0.92 \mathrm{MW}$, in other words almost half the available power is not deposited into the plasma and thus has no opportunity to be converted to useful thrust power.

On the other hand, inclusion of such physics substantially elevated the plasma voltage (and thus plasma power deposition) implying that the predominant inefficiencies are due to frozen-flow losses. Furthermore, this is accurately illustrated by a power budget accounting for individual energy deposition to different modes and external losses. This is given below with the value in parenthesis corresponding to calculated values under classical transport:

$$
\begin{array}{ll}
\text { Axial Thrust Power } & =0.5 \mathrm{MW}(0.377 \mathrm{MW}) \\
\text { Radial Thrust Power } & =0.123 \mathrm{MW}(0.08 \mathrm{MW}) \\
\text { Ionization Power } & =0.608 \mathrm{MW}(0.352 \mathrm{MW}) \\
\text { Thermal Power } & =0.445 \mathrm{MW}(0.251 \mathrm{MW}) \\
\text { Electrode Conduction } & =0.154 \mathrm{MW}(0.027 \mathrm{MW}) \\
\text { Fall Voltage Power } & =0.17 \mathrm{MW}(0.92 \mathrm{MW})
\end{array}
$$

The comparisons of the two-dimensional current distribution to experiment shown in Fig. 8 leave no doubt as to the validity of the formulation. Further support is provided by a simple calculation of the total power necessary to fully ionize the hydrogen propellant at $1.37 \mathrm{~g} / \mathrm{s}$. This requirement is of the order of $2 \mathrm{MW}$ which in turn insinuates that the propellant may be highly incompletely ionized; interrogation of the $\mathrm{MACH} 2$ calculated average degree of ionization did indeed confirm the implication. Specifically, such ionization was less than $10^{-3}$ in the straight section of the discharge chamber, implying that electron-ion collisions do not dominate. It is noteworthy that comparisons of the total 
thrust alone could not have offered such understanding or suggested inclusion of the improved model for the electrical diffusivity as both calculated thrust values can not be distinguished within experimental error.

Based on the above understanding the MACH2 simulations will proceed to model the range of current levels performed by the MY-II experiments. This should provide elevated confidence in the code"s capabilities as well as generalize the aforementioned deductions for this regime of operation. Concurrently, $\mathrm{MACH} 2$ will be utilized to guide the design toward proper expansion nozzles that can recover some of the frozen-flow losses calculated above. In addition, code improvements are underway that include sheath models to calculate fall voltage and study electrode erosion when utilized in conjunction to the already existing ablation models.

\section{CONCLUDING REMARKS}

A MW-class pulsed MPD thruster test facility is currently operational at the NASA Glenn Research Center. This facility is used as a testbed for the economical evaluation of new high power MPD thruster designs, with the goal of transitioning the most promising designs to a MWclass steady-state experimental facility. The steady-state facility, currently being refurbished and upgraded for high power operation, will be used to evaluate thruster performance, material and life issues at power levels from $0.1-\mathrm{MW}$ to $1-\mathrm{MW}$. In concert with the experimental program, the MACH2 code is being used to understand the basic physics of high power MPD thruster operation, and has already led to new insights and new directions toward efficient gas-fed thruster designs.

Near-term plans for the NASA GRC high power MPD thruster program include use of the pulsed test facility to validate specific MW-class thruster designs developed using the MACH2 numerical simulations. These designs include self-field devices with contoured expansion nozzles to recapture frozen flow losses, and applied-field thrusters operated with and without expansion nozzles. Efficient quasi-steady thruster designs will be fabricated for continuous operation and tested in the 1-MW steadystate facility. Concurrent research efforts will be undertaken to improve cathode life and reduce anode wear, leading to efficient, long-life electromagnetic thrusters. The strong synergy between numerical modeling and experimental testing at GRC provides a solid basis for the development and eventual deployment of high power MPD thrusters capable of meeting the demanding propulsion requirements of future NASA missions.

\section{REFERENCES}

1. Gilland, J.. "Mission and System Optimization of Nuclear Electric Propulsion Vehicles for Lunar and Mars Missions," NASA CR-189058, Dec 1991.

2. Gilland, J. and Oleson, S., "Combined High and Low Thrust Propulsion for Fast Piloted Mars Missions," NASA CR-190788, Nov 1992.

3. Filliben, J.D., "Electric Propulsion for Space Applications," CPTR96-64, Chemical Propul-sion Information Agency. Columbia, MD, 1996.

4. Oleson, S., "Advanced Electric Propulsion for Space Solar Power Satellites," NASA/TM-1999-209307, Aug 1999.

5. Nerheim, N. and Kelly, A., "A Critical Review of the Magnetoplasmadynamic Thruster for Space Applications," NASA CR-92139, Feb 1968.

6. Sovey. J. and Mantenieks, M., "Performance and Lifetime Assessment of Magnetoplasmadynamic Arc Thruster Technology," NASA TM-101293, 1988.

7. Myers, R., Mantenieks, M., and LaPointe, M., "MPD Thruster Technology," NASA TM-105242, 1991.

8. Tikhonov, V., Semenikhin, S., Brophy, J., and Polk, J., "Performance of 130-kW MPD Thruster with an External Applied Field and Lithium as Propellant," IEPC-97-120, 25th Intemational Electric Propulsion Conference, Cleveland, OH 1997.

9. Kudysis, A., Emsellem, G., Cassady, L., Polk, J., and Choueiri, E., "Lithium Mass Flow Control for High Power Lorentz Force Accelerators", AIP Conference Proceedings 552. Space Technology and Applications International Forum (STAIF) 2001, M. El-Genk (ed), American Institute of Physics, Feb 2001, pp. 908-915.

10. Polk. J., Tikhonov, V., Semenikhim, S., and Kim, V., "Cathode Temperature Reduction by Addition of Barium in High Power Lithium Plasma Thrusters", AIP Conference Proceedings 504, Space Technology and Applications International Forum (STAIF) 2000, M. El-Genk (ed), American Institute of Physics, Feb 2000, pp. 1556-1563. 
11. Choueiri. E. and Zeimer, J., "Quasi-Steady Magnetoplasmadynamic Thruster Measured Performance Database", AIAA-98-3472, 34th Joint Propulsion Conference. Cleveland, OH, July 1998.

12. Mikellides, P. G., Turchi, P. J., and Roderick, N. F., "Applied-Field Magnetoplasmadynamic Thrusters, Part 1: Numerical Simulations Using the MACH2 Code". $J$. Propulsion and Power. 16 (5), Sept-Oct 2000, pp. 887-893.

13. Mikellides, P. G., and Turchi, P. J "Applied-Field Magnetoplasmadynamic Thrusters. Part 2: Analytic Expressions for Thrust and Voltage", J. Propulsion and Power, 16 (5), Sept-Oct 2000, pp. 894-901.

14. Sovey, J., Mantenieks, M., Haag. T., Raitano, P., and Parkes, J., "Test Facility and Preliminary Performance of a 100-kW Class MPD Thruster". NASA TM-102021, May 1989.

15. Myers. R., "Scaling of 100-kW Class Applied-Field MPD Thrusters". AIAA-92-3462, presented at the 28th Joint Propulsion Conference, Nashville. TN, July 1992.

16. Myers, R., Mantenieks, M., and Sovey, J., "Geometric Effects in Applied-Field MPD Thrusters", AIAA-90-2699, presented at the 21st International Electric Propulsion Conference, Orlando, FL, July 1990.

17. Myers. R., "Applied-Field MPD Thruster Geometry Effects", NASA CR-187163, August 1991.

18.Myers, R., "Applied-Field MPD Thruster Performance with Hydrogen and Argon Propellants", J. Propulsion and Power, 9 (5), Sep-Oct 1993, pp. 781-784.

19. Auweter-Kurtz, M., Epple, J., Habiger, H., Kurtz, H., Loesener, O., Messerschmidt, E., and Mulzer, D., "Steady State MPD Devices for Reentry Simulation", IEPC-88-114, presented at the 20th International Electric Propulsion Conference, Garmisch-Partenkirchen, W. Germany, Oct 1988.

20. Auweter-Kurtz, M., Boie, C., Kaeppeler, H., Kurtz, H., Schrade. H., Sleziona. P., Wager, H., and Wegmann, T.. "Magnetoplasmadyanmic Thrusters-Design Criteria and Numerical Evaluation", presented at the International Symposium on Simulation and Design of Applied Electromagnetic Systems, Sapporo, Japan, Jan 26-30, 1993.
21. Peterkin, R.E. and Frese, M.H., MACH: A Reference Manual-First Edition. Air Force Research Laboratory, Kirtland AFB, New Mexico. September 14, 1998.

22. Frese, M.H., "MACH2: A Two-Dimensional Magnetohydrodynamics Simulation Code for Complex Experimental Configurations," AMRC-R-874, September 1986.

23. Peterkin, R.E., Jr., and Frese, M.H., "A Material Strength Capability for MACH2," MRC/ABQ-R-1191, October 1989.

24. Mikellides, P.G., "A Theoretical Investigation of Magnetoplasmadynamic Thrusters," Ph.D. Dissertation, Department of Aeronautical and Astronautical Engineering, The Ohio State University, 1994.

25. Turchi, P.J. Mikellides, I.G. Mikellides, P.G. and H. Kamhawi, "Pulsed Plasma Thrusters for Microsatellite Propulsion: Techniques for Optimization," MicroPropulsion for Small Spacecraft, Progress in Astronautics and Aeronautics, Hardcover ISBN: 1-56347-448-4, Copyright 2000.

26. Braginskii, S.I., "Transport Processes in a Plasma," in Review of Plasma Physics, M.A. Leontovich, ed. Consultants Bureau, New York, 1965.

27. Douglas, M.R., "Radiation Production from Stagnating Compact Toroids Employing a Nonequilibrium Radiation Diffusion Model," Ph.D. Dissertation, U. of New Mexico, 1994.

28. Holian, K.S., ed, "T-4 Handbook of Material Properties Data Base.. Vol Ic: EOS," LA-1160-MS, Los Alamos National Laboratory, Los Alamos, NM, November, 1984.

29. Buff, J. et. al.. "Enhancement of the Radiation Yield in Plasma Flow Switch Experiments," MRC/ABQ-R1171, Mission Research Corporation, Albuquerque, NM, 1988. Also see: IEEE Transactions on Plasma Science, 15,6 , pp. 766-771, 1987.

30. Peterkin, R.E., Jr., et. al., "Simulations of Staged Solid Shell Implosions to Produce Fusion," AIAA Preprint 95-2899, $31^{\text {st }}$ AIAA Joint Propulsion Conference and Exhibit, San Diego, CA, 1995. 
31. Degnan, J.H., Peterkin, R.E., Jr. et. al., "Compact Toroid Formation, Compression, and Acceleration." Physics of Fluids, B5 (8), 2938, 1993.

32. Degnan. J.H., et. al., "Electromagnetic Implosion of Spherical Liner." Phys. Rev. Lett., 74 (1), 98, 1995.

33. Stamper, J.A., et. al., "Aneurysms in laser-driven last waves," Physics of Fluids, 31 (11), 3353, 1988.

34. Mikellides, P.G., Turchi, P.J., and Mikellides, I.G., "Design of a Fusion Propulsion System, Part 1: Gigawatt-Level Magnetoplasmadynamic Source," Joumal of Propulsion and Power, submitted Sept. 2000. Log No. B4106. IEPC Preprint 99-013.

35. Mikellides, I.G., Mikellides, P.G., Turchi, P.J. and York, T.M."Design of a Fusion Propulsion System. Part 2: Numerical Simulation of Magnetic-Nozzle Flows." Journal of Propulsion and Power, submitted Sept. 2000. Log No. B4107. AIAA Preprint 00-3367.

36. Tahara, H., Kagaya, Y. and T. Yoshikawa, "QuasiSteady MPD Arcjets with Applied Magnetic Fields," AIAA-85-2001, $18^{\text {th }}$ International Electric Propulsion Conference, Alexandria, VA, 1985.

37. Tahara, H., Kagaya, Y. and Yoshikawa, T. "QuasiSteady Magnetoplasmadynamic Thrusters with Applied Magnetic Fields for Near-Earth Missions," Journal of Propulsion, $\underline{5}$ (6), 713, Nov.-Dec. 1989.

38. Brode, R.B., Energy Dependence of electron-atom elastic cross sections, Review in Modern Physics, $\underline{5}$ p. $257,1933$. 


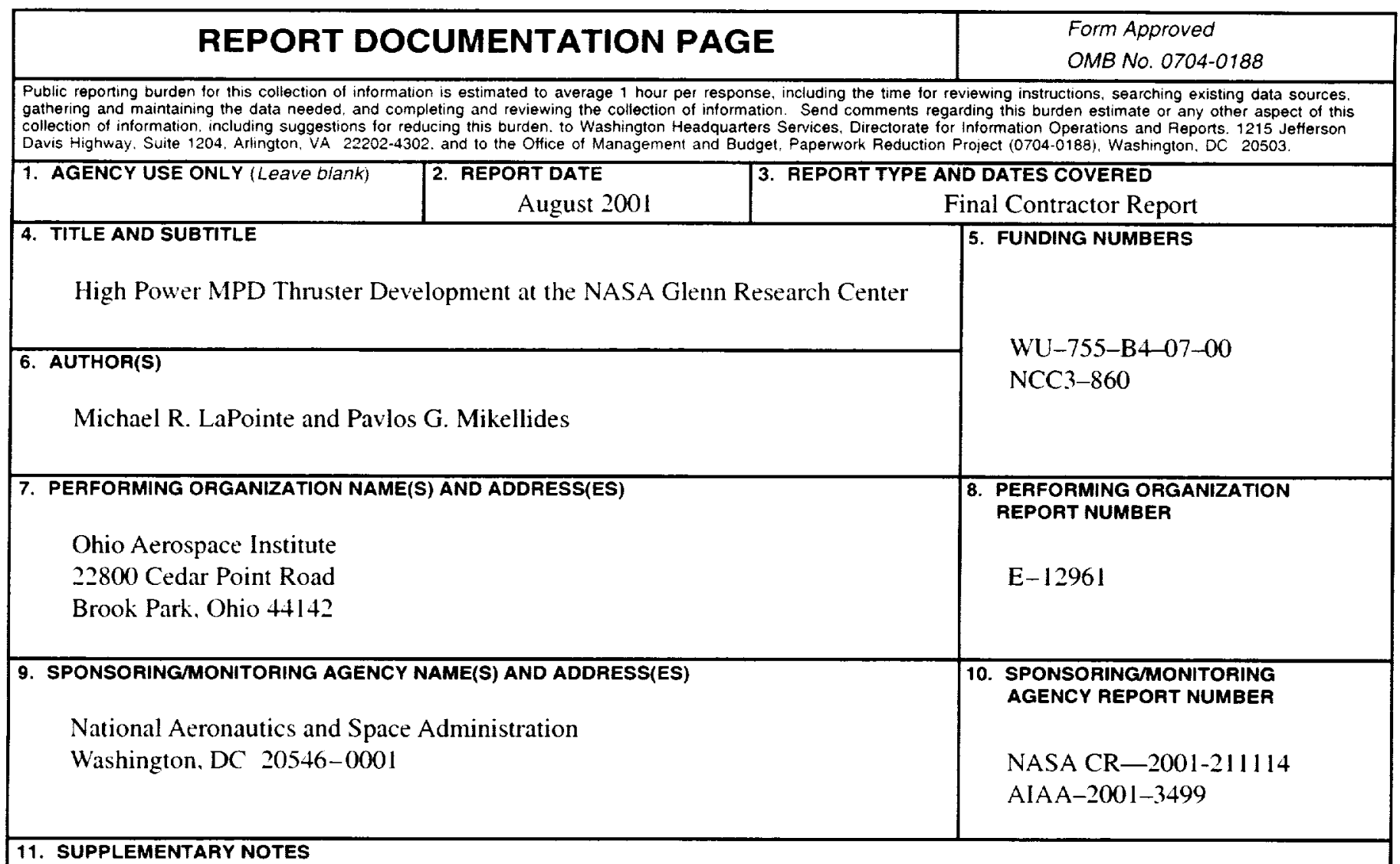

Prepared for the 37th Joint Propulsion Conference and Exhibit cosponsored by the AIAA, ASME, SAE, and ASEE, Salt Lake City, Utah, July 8-11. 2001. Project Manager. Dhanireddy Reddy. Power and On-Board Propulsion Technology Division. NASA Glenn Research Center, organization code 5430, 216-4.33-8133.

\begin{tabular}{|l|l|}
\hline 12a. DISTRIBUTION/AVAILABILITY STATEMENT & 12b. DISTRIBUTION CODE
\end{tabular}

Unclassified - Unlimited

Subject Category: $20 \quad$ Distribution: Nonstandard

Available electronically at hup://gilers,grc.nasa,gov/GLTRS

This publication is available from the NASA Center for AeroSpace Information. 301-621-0390.

13. ABSTRACT (Maximum 200 words)

Propulsion requirements for large platform orbit raising, cargo and piloted planetary missions, and robotic deep space exploration have rekindled interest in the development and deployment of high power electromagnetic thrusters. Magnetoplasmadynamic (MPD) thrusters can effectively process megawatts of power over a broad range of specific impulse values to meet these diverse in-space propulsion requirements. As NASA's lead center for electric propulsion, the Glenn Research Center has established an MW-class pulsed thruster test facility and is refurbishing a high-power steady-state facility to design, build, and test efficient gas-fed MPD thrusters. A complimentary numerical modeling effort based on the robust $\mathrm{MACH} 2$ code provides a well-balanced program of numerical analysis and experimental validation leading to improved high power MPD thruster performance. This paper reviews the current and planned experimental facilities and numerical modeling capabilities at the Glenn Research Center and outlines program plans for the development of new. efficient high power MPD thrusters.

\begin{tabular}{|c|c|c|c|}
\hline 14. SUBJECT TERMS & & & 15. NUMBER OF PAGES \\
\hline \multicolumn{3}{|c|}{$\begin{array}{l}\text { Propulsion; Electric propulsion; Electromagnetic propulsion; } \\
\text { Plasma propulsion; Magnetoplasmadynamic thruster }\end{array}$} & $\begin{array}{l}17 \\
\text { 16. PRICE CODE }\end{array}$ \\
\hline $\begin{array}{l}\text { 17. SECURITY CLASSIFICATION } \\
\text { OF REPORT } \\
\text { Unclassified }\end{array}$ & $\begin{array}{l}\text { 18. SECURITY CLASSIFICATION } \\
\text { OF THIS PAGE } \\
\text { Unclassified }\end{array}$ & $\begin{array}{l}\text { 19. SECURITY CLASSIFICATION } \\
\text { OF ABSTRACT } \\
\text { Unclassified }\end{array}$ & 20. LIMITATION OF ABSTRACT \\
\hline VSN 7540-01-280-5500 & & & $\begin{array}{l}\text { andard Form } 298 \text { (Rev. 2-89) } \\
\text { scribed by ANSI Std. Z39-18 } \\
3-102\end{array}$ \\
\hline
\end{tabular}


$\longrightarrow$

\section{-}


